\title{
Solar UV radiation measurements in Marambio, Antarctica, during years 2017-2019
}

\author{
Margit Aun ${ }^{1,2}$, Kaisa Lakkala ${ }^{1,3}$, Ricardo Sanchez ${ }^{4}$, Eija Asmi ${ }^{1,4}$, Fernando Nollas ${ }^{4}$, Outi Meinander ${ }^{1}$, \\ Larisa Sogacheva $^{1}$, Veerle De Bock ${ }^{5}$, Antti Arola ${ }^{1}$, Gerrit de Leeuw ${ }^{1, a}$, Veijo Aaltonen ${ }^{1}$, David Bolsée ${ }^{6}$, \\ Klara Cizkova $^{7,8}$, Alexander Mangold ${ }^{5}$, Ladislav Metelka ${ }^{7}$, Erko Jakobson ${ }^{2}$, Tove Svendby ${ }^{9}$, Didier Gillotay ${ }^{6}$, and \\ Bert Van Opstal ${ }^{6}$ \\ ${ }^{1}$ Climate Research Programme, Finnish Meteorological Institute, Helsinki, Finland \\ ${ }^{2}$ Tartu Observatory, University of Tartu, Tõravere, Estonia \\ ${ }^{3}$ Space and Earth Observation Centre, Finnish Meteorological Institute, Sodankylä, Finland \\ ${ }^{4}$ Servicio Meteorológico Nacional, Buenos Aires, Argentina \\ ${ }^{5}$ Royal Meteorological Institute of Belgium, Brussels, Belgium \\ ${ }^{6}$ Royal Belgian Institute for Space Aeronomy, Brussels, Belgium \\ ${ }^{7}$ Solar and Ozone Observatory, Czech Hydrometeorological Institute, Hradec Králové, Czech Republic \\ ${ }^{8}$ Institute of Geography, Masaryk University, Brno, Czech Republic \\ ${ }^{9}$ NILU - Norwegian Institute for Air Research, Kjeller, Norway \\ ${ }^{a}$ currently at: R\&D Satellite Observations, Royal Netherlands Meteorological Institute (KNMI), De Bilt, the Netherlands
}

Correspondence: Margit Aun (margit.aun@ut.ee)

Received: 3 October 2019 - Discussion started: 7 November 2019

Revised: 9 April 2020 - Accepted: 13 April 2020 - Published: 25 May 2020

\begin{abstract}
In March 2017, measurements of downward global irradiance of ultraviolet (UV) radiation were started with a multichannel GUV-2511 radiometer in Marambio, Antarctica $\left(64.23^{\circ} \mathrm{S} ; 56.62^{\circ} \mathrm{W}\right)$, by the Finnish Meteorological Institute (FMI) in collaboration with the Servicio Meteorológico Nacional (SMN). These measurements were analysed and the results were compared to previous measurements performed at the same site with the radiometer of the Antarctic NILU-UV network during 2000-2008 and to data from five stations across Antarctica. In 2017/2018 the monthly-average erythemal daily doses from October to January were lower than those averaged over 2000-2008 with differences from $2.3 \%$ to $25.5 \%$. In $2017 / 2018$ the average daily erythemal dose from September to March was $1.88 \mathrm{~kJ} \mathrm{~m}^{-2}$, while in $2018 / 2019$ it was $23 \%$ larger $\left(2.37 \mathrm{~kJ} \mathrm{~m}^{-2}\right)$. Also at several other stations in Antarctica the UV radiation levels in 2017/2018 were below average. The maximum UV indices (UVI) in Marambio were 6.2 and 9.5 in 2017/2018 and 2018/2019, respectively, whereas during years 2000-2008 the maximum was 12 . Cloud cover, the strength of the polar vortex and the stratospheric ozone de-
\end{abstract}

pletion are the primary factors that influence the surface UV radiation levels in Marambio. The lower UV irradiance values in 2017/2018 are explained by the high ozone concentrations in November, February and for a large part of October. The role of cloud cover was clearly seen in December, and to a lesser extent in October and November, when cloud cover qualitatively explains changes which could not be ascribed to changes in total ozone column (TOC). In this study, the roles of aerosols and albedo are of minor influence because the variation of these factors in Marambio was small from one year to the other. The largest variations of UV irradiance occur during spring and early summer when noon solar zenith angle (SZA) is low and the stratospheric ozone concentration is at a minimum (the so-called ozone hole). In 2017/2018, coincident low total ozone column and low cloudiness near solar noon did not occur, and no extreme UV indices were measured. 


\section{Introduction}

Ultraviolet (UV) radiation is part of the Sun's electromagnetic radiation in the wavelength range from 100 to $400 \mathrm{~nm}$; UV radiation at wavelengths smaller than $280 \mathrm{~nm}$ does not reach the surface of the Earth (UNEP, 1998). The amount of UV radiation reaching the ground depends on various factors that can be divided into geometrical (including the distance between the Sun and the Earth and the solar zenith angle (SZA) at a given location) and geophysical factors (Kerr, 2005). Examples of the latter are clouds, ozone $\left(\mathrm{O}_{3}\right)$ and aerosol particles, which can absorb or scatter UV radiation - absorption by $\mathrm{O}_{3}$ is the reason why UV radiation at wavelengths shorter than $280 \mathrm{~nm}$ does not reach the ground. Any change in these factors will affect UV irradiance. One of the most important factors affecting UV radiation is cloud cover. Clouds can reduce UV irradiance by as much as $85 \%$ or more (Kerr, 2005; Kylling et al., 2000), but they can also enhance UV irradiance through strong scattering up to $50 \%$ (Feister et al., 2015). The effect of clouds is determined by the macro- and micro-physical properties of the clouds (Sabburg and Calbo, 2009). In Antarctica, less information is available about clouds due to the harsh conditions, which create unique conditions (low temperatures and moisture) for cloud formation (Bromwich et al., 2012). The variability of cloud cover is dependent on the location; its weather conditions, like prevailing wind; and topography.

The UV irradiance measured at the surface is also affected by the surface albedo, which determines how much of the UV radiation is reflected back to the atmosphere (Kerr, 2005). This effect is most important when the surface is covered with snow, because snow has a high albedo and therefore reflects more radiation, which in turn can be scattered back to the surface.

In the 1980s, $\mathrm{O}_{3}$ depletion in Antarctica was discovered and this reduction was especially strong during the Antarctic spring (Farman et al., 1985). Since then, successful measures, such as agreed upon in the Montreal Protocol (adopted in 1987), have been taken to protect the ozone layer. Thanks to these efforts, concentrations of $\mathrm{O}_{3}$-depleting substances have declined since the 1990s (WMO, 2018). However, a recent study discovered that the rate of decline of $\mathrm{O}_{3}$-destructive trichlorofluoromethane (CFC-11) has slowed substantially - about $50 \%$ since 2012 (Montzka et al., 2018). Although the gradual loss of stratospheric $\mathrm{O}_{3}$ over the years has stopped and the first signs of recovery (such as a statistically significant positive trend in ozone observed over the Antarctic in September since 2000) have been noted, the springtime reduction of $\mathrm{O}_{3}$ concentration that leads to the ozone hole still exists over Antarctica (Solomon et al., 2016). According to the latest WMO ozone report (WMO, 2018), there is some indication that the Antarctic ozone hole has diminished in size and depth since the year 2000, but it is affected by meteorological conditions such as temperature and wind, making the natural variability of total ozone column
(TOC) large and therefore the detection of recovery difficult. In Antarctica, TOC is strongly affected by the presence of the polar vortex. It establishes conditions with extremely low temperatures and the formation of polar stratospheric clouds (PSCs), which are essential for chemical processes to activate compounds capable of destroying $\mathrm{O}_{3}$. At the same time, the characteristics of the polar vortex provide a dynamic isolation that disables the mixing of mid-latitude air with the polar air and therefore sustain the compounds needed for $\mathrm{O}_{3}$ destruction and the formation of the ozone hole (Schoeberl and Hartmann, 1991). To detect the changes and the expected recovery, continuous measurements of TOC and UV irradiance must be carried out in the region. These measurements also provide the possibility to analyse effects of changes in other climate parameters, such as cloud and aerosol properties and surface albedo, on the UV irradiance near the surface. This is especially important because of the ongoing interaction between climate change and these parameters (IPCC, 2014). To promote the research of stratospheric $\mathrm{O}_{3}$ and UV radiation in Antarctica, the Finnish Meteorological Institute (FMI) started UV irradiance measurements in Marambio $\left(64.23^{\circ} \mathrm{S}\right.$; $56.62^{\circ} \mathrm{W}$ ) in collaboration with Argentina's Servicio Meteorológico Nacional (SMN) in March 2017. These measurements are used to assess the current situation, and they can be compared to earlier measurements from the NILU-UV Antarctic network (Lakkala et al., 2018), whose data from 2000 to 2008 serve as a reference for times when the recovery of the ozone layer was at its beginning. The Antarctic NILU-UV radiometer network was established as a collaboration between the Spanish State Meteorological Agency (AEMET), Argentina's National Directorate of the Antarctic - Argentinian Antarctic Institute (DNA-IAA) and FMI in 1999/2000. Within the network, UV irradiance measurements were carried out from 2000 to 2013 in Marambio, Ushuaia Global Atmosphere Watch (GAW) station, in southern Argentina $\left(54.82^{\circ} \mathrm{S}, 68.32^{\circ} \mathrm{W}\right)$ and Belgrano, Antarctica $\left(77.87^{\circ} \mathrm{S}, 34.63^{\circ} \mathrm{W}\right)$ (Lakkala et al., 2018). Due to the harsh meteorological conditions in these polar regions, including very low temperatures and severe snow storms, proper quality assurance procedures are very important (Lakkala et al., 2005). For Marambio, UV irradiance measured during the period 2000-2010 was found reliable and was analysed and compared to UV data measured simultaneously at Ushuaia in Lakkala et al. (2018). At both stations, daily erythemal UV doses during spring $\mathrm{O}_{3}$ loss episodes could even exceed doses in the summer when they are naturally supposed to be higher due to lower noon SZA. The highest daily maximum UV index (UVI) measured in Marambio was 12, in November 2007; in Ushuaia the highest daily maximum UVI was 13, which was measured in November of the years 2003 and 2009.

The aim of this paper is to present the results of UV irradiance measurements in Marambio from March 2017 to March 2019 and to compare them with those from 2000 to 2008 and also with UV measurements at other Antarctic stations. 


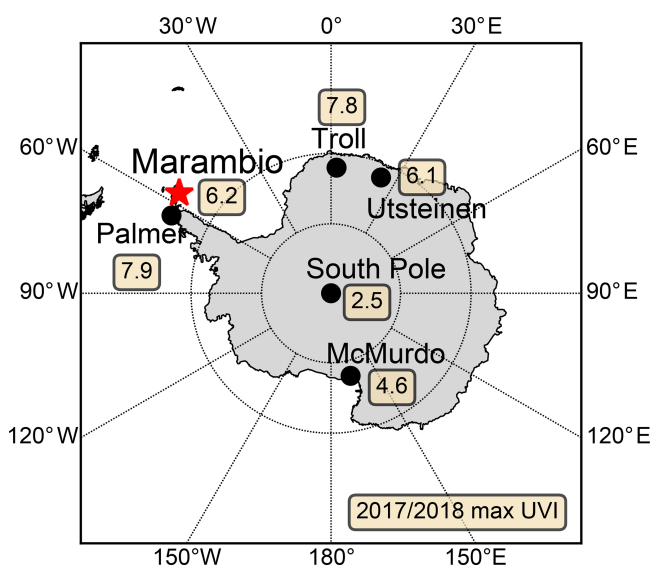

Figure 1. Locations of the stations included in the analysis. The numbers next to the sites show the corresponding maximum UVI measured during the season 2017/2018.

Including different measurement sites provides an opportunity to investigate whether differences between the latest solar seasons and previous measurements are common for different Antarctic stations or whether they are region specific, as the factors influencing UV radiation vary widely over the continent.

\section{Data and methods}

In addition to measurements at Marambio, data from five more research sites are used in the analysis: the Princess Elisabeth Station at Utsteinen and the stations Troll, Palmer Station, McMurdo Station and Amundsen-Scott South Pole Station (referred to hereafter as South Pole Station). The locations of the stations together with the maximum UVI during the season 2017/2018 are shown in Fig. 1, and the summary information about the location, instruments and used data periods is presented in Table 1.

In this work, mainly two different UV products derived from the measurements are used. The first parameter is the erythemal daily dose $(D)$ (in $\mathrm{J} \mathrm{m}^{-2}$ ), which is calculated from the dose rate of erythemal irradiance $(E)$ (in $\mathrm{W} \mathrm{m}^{-2}$ ) from the beginning of the day (T1) to the end (T2).

$$
D=\int_{T 1}^{T 2} E(T) \mathrm{d} T
$$

$E$ is defined as the effective irradiance obtained by integrating the spectral irradiance weighted by the CIE (Commission Internationale de 1'Eclairage) reference action spectrum for UV-induced erythema on the human skin up to $400 \mathrm{~nm}$ and normalized to 1.0 below $298 \mathrm{~nm}$ (McKinlay and Diffey, 1987).

The second parameter is UVI, which is calculated by multiplying the effective erythemal irradiance (in $\mathrm{W} \mathrm{m}^{-2}$ ) by
$40 \mathrm{~m}^{2} \mathrm{~W}^{-1}$ and has no units (Fioletov et al., 2010). As typically the UVI at northern high latitudes varies between 0 and 6 (at sea level and latitudes above $60^{\circ}$ ) (e.g. Bernard et al., 2019), there is an interest to know the variation range at similar latitudes in the Southern Hemisphere. For this purpose, the maximum daily UVI was analysed in this study.

In the current study, the data were divided into two periods $-2017 / 2018$ and 2018/2019. To take the local annual solar cycle into account, solar seasons were used instead of calendar years. In the case of no polar night, a solar season is defined as the period lasting from 1 July to 30 June the next year. For most of the stations in Antarctica, the measurement period is much shorter; e.g. at South Pole the solar season lasts only from September to March. A full day was defined using UTC time both for the UV and proxy data. For each day, the daily erythemal dose as well as the maximum daily UVI was determined.

For describing the effect of $\mathrm{O}_{3}$ on UV irradiance, the radiation amplification factor (RAF) has been used. RAF is defined as the percentage increase in UV radiation that would result from a $1 \%$ decrease in TOC (UNEP, 1998). For small changes, RAF can be calculated as

$\mathrm{RAF}=-\frac{\Delta E / E}{\Delta \mathrm{TOC} / \mathrm{TOC}}$,

where $\Delta E$ and $\triangle \mathrm{TOC}$ are the respective changes of UV irradiance $(E)$ and ozone (TOC). For larger changes, a powerlaw equation should be used as in McKenzie et al. (2011):

$\frac{E^{+}}{E^{-}}=\left(\frac{\mathrm{TOC}^{-}}{\mathrm{TOC}^{+}}\right)^{\mathrm{RAF}}$

where + represents the case with the higher TOC.

The RAF value depends on multiple factors like SZA, clouds and TOC (Antón et al., 2016). For erythemal irradiance an average value of 1.2 can be used (Antón et al., 2016; McKenzie et al., 2011; Lakkala et al., 2018).

\subsection{Marambio station}

The Marambio station (Marambio Base) is located on an island east of the Antarctic Peninsula (see Fig. 1). The monthly-mean temperatures in Marambio vary between -30 and $+10^{\circ} \mathrm{C}$. During most of the year, the soil is frozen and covered with snow. The prevailing wind directions are from the southwest and the northwest, and the wind speed can reach values close to $100 \mathrm{~km} \mathrm{~h}^{-1}$.

The station is part of the World Meteorological Organization (WMO) regional station network and data are regularly reported to the World Ozone and UV Data Centre (WOUDC).

\subsubsection{UV measurements}

Since March 2017, GUV-2511 multifilter radiometers, manufactured by Biospherical Instrument Inc., are used to mea- 
Table 1. Measurement stations with their locations, altitudes, used UV instrument, daily product types (erythemal dose, $D_{\text {ery }}$; UVA dose, $\left.D_{\text {UVA }}\right)$ and period of data used in the analysis.

\begin{tabular}{|c|c|c|c|c|c|}
\hline Station & Location & $\begin{array}{l}\text { Height } \\
\text { (a.s.l.) }\end{array}$ & $\begin{array}{l}\text { UV instrument } \\
\text { type }\end{array}$ & Product & $\begin{array}{r}\text { Period } \\
\text { included }\end{array}$ \\
\hline Marambio Base & $64.23^{\circ} \mathrm{S}, 56.62^{\circ} \mathrm{W}$ & $198 \mathrm{~m}$ & $\begin{array}{l}\text { NILU-UV } \\
\text { GUV }\end{array}$ & $\begin{array}{l}\text { Max UVI, } D_{\text {ery }} \\
\text { Max UVI, } D_{\text {ery }}, D_{\text {UVA }}\end{array}$ & $\begin{array}{l}2000-2008 \\
2017-2019\end{array}$ \\
\hline $\begin{array}{l}\text { Princess Elisabeth } \\
\text { Antarctica }\end{array}$ & $71.95^{\circ} \mathrm{S}, 23.35^{\circ} \mathrm{E}$ & $1390 \mathrm{~m}$ & $\begin{array}{l}\text { Brewer } \\
\text { UVB pyranometer } \\
\text { MS212W }\end{array}$ & $\begin{array}{l}\text { Max UVI } \\
\text { Noon UVI }\end{array}$ & $\begin{array}{l}2017-2019 \\
2017-2018\end{array}$ \\
\hline Troll & $72.01^{\circ} \mathrm{S}, 2.53^{\circ} \mathrm{E}$ & $1553 \mathrm{~m}$ & NILU-UV & Max UVI & 2017-2019 \\
\hline Palmer Station & $64.77^{\circ} \mathrm{S}, 64.05^{\circ} \mathrm{W}$ & $21 \mathrm{~m}$ & SUV-100 & Max UVI & $\begin{array}{l}2000-2008 \\
2017-2019\end{array}$ \\
\hline McMurdo Station & $77.83^{\circ} \mathrm{S}, 166.67^{\circ} \mathrm{E}$ & $183 \mathrm{~m}$ & SUV-100 & Max UVI & $\begin{array}{l}2000-2008 \\
2017-2019\end{array}$ \\
\hline South Pole Station & $90.0^{\circ} \mathrm{S}, 0.0^{\circ} \mathrm{E}$ & $2835 \mathrm{~m}$ & SUV-100 & Max UVI & $\begin{array}{l}2000-2008 \\
2017-2019\end{array}$ \\
\hline
\end{tabular}

sure UV irradiance in Marambio. These instruments measure the downwelling irradiance at wavelengths of 305,313 , $320,340,380,555 \mathrm{~nm}$ and photosynthetically active radiation (PAR, 400-700 nm), which are provided as 1 min averages. The full width at half maximum (FWHM) of the first six channels is $10 \mathrm{~nm}$. The angular response of the instrument determined by the manufacturer is $0 \%-5 \%$ from 0 to $70^{\circ}$ and $\pm 10 \%$ from 71 to $85^{\circ}$. The GUV instrument is also used for UV monitoring at the Antarctic and Arctic sites of the United States National Science Foundation (NSF) UV Monitoring Network (e.g. Bernhard et al., 2005), and the instrument is robust enough to stand harsh measurement conditions including strong winds, snow, frost formation, and rapidly changing or extreme temperatures. As the response of the instrument is sensitive to temperature and humidity, the instrument needs to be adequately sealed and temperature stabilized. The internal temperature of the GUV in Marambio is maintained at $40^{\circ} \mathrm{C}$, which was found to be enough to keep the instrument clean from frost and snow.

Two GUV instruments are used for the UV measurements in Marambio - while one of them is measuring in Marambio the other one is in calibration either in Finland or in the United States (Lakkala et al., 2020). The instruments are switched annually in order to transfer the latest calibration to Marambio and thus maintain the homogeneity of the measurement time series.

The calibration of the instruments is performed using the method presented in Dahlback (1996) and explained in detail in Bernhard et al. (2005). The method includes calibration against a high-quality spectroradiometer which, for the GUV radiometers of Marambio, is a SUV-100 spectroradiometer, from the NSF UV Monitoring Network, whose irradiance scale is traceable to the US National Institute of Standards and Technology (NIST) (Booth et al., 1994). The calibration includes two steps: first, a calibration coefficient is calculated for each channel by performing a regression against measurements of the cosine-error-corrected SUV-100 spectroradiometer. Prior to the regression, the spectra of the SUV100 are weighted with the spectral response functions of the GUV radiometer. The results are the so-called "responseweighted" irradiances (Seckmeyer et al., 2010) as the spectral response function of the GUV is taken into account. The second step includes the calculation of the UV products. The method is also described in Dahlback (1996) and discussed in detail for the GUV radiometers in Bernhard et al. (2008). A UV product $P$ is calculated using a linear combination of the dark-signal-corrected signals of the GUV radiometer UV channels $\mathrm{V}_{i}$ :

$P=\sum_{i=0}^{5} a_{i} V_{i}$

where the coefficient $a_{i}$ depends on the calibration factor derived in the first step and the used biological action spectrum, e.g. erythemal response for erythemally weighted irradiances. The coefficients are determined by solving a system of linear equations as described by Bernhard et al. (2008), taking into account the atmospheric conditions at the site (e.g. range of total ozone and surface albedo). The validation of UV products calculated using this method is discussed in Bernhard et al. (2005). The validation results show that the UV index from a GUV instrument can be within $5 \%$ from a well-calibrated spectroradiometer for SZAs smaller than $78^{\circ}$.

The quality control of the measurements in Marambio includes regular cleaning of the diffusor and checking of the levelling. The data are plotted on the web page http: //fmiarc.fmi.fi/sub_sites/GUVant/ (last access: 5 February 2020), which enables quick quality control by eye. The com- 
plete calibration and quality assurance procedure is described in detail in Lakkala et al. (2020). It includes solar comparisons with spectroradiometers at Sodankylä, whose measurement site has similar atmospheric conditions: high SZA, rapidly changing cloud cover, a clean atmosphere and ozone profiles typical for high latitudes. The results show that the differences are within $6 \%$ for comparisons made in 20162018 for SZAs lower than $60^{\circ}$. Solar comparisons are also performed at Marambio each time there is a switch of instruments. The first switch was made in November 2018, and the difference between the two GUV radiometers was $4 \%-6 \%$. The difference was due to a drift in the channels of the GUV, which was in regular operation in Marambio. A drift of $2 \%$ to $5 \%$ was observed depending on the channel, which is typical for a new instrument. Taking into account the drift of the instrument and the uncertainties in the transfer of the calibration from the SUV-100 to the GUV, the uncertainty of the SUV-100 measurements, and the uncertainty of the conversion from response-weighted irradiance to the $\mathrm{UV}$ product $P$, the expanded $(k=2)$ uncertainty of the studied GUV measurements was calculated to be $9 \%$ for SZAs smaller than $80^{\circ}$ (Lakkala et al., 2020).

In addition, the Marambio NILU-UV daily dose and maximum UV index time series described in Lakkala et al. (2018) were used. The NILU-UV is a multichannel radiometer, which measures radiation at five UV channels and one PAR channel. The central wavelengths of the UV channels are at 305, 312, 320, 340 and $380 \mathrm{~nm}$ and the FWHM for each channel is around $10 \mathrm{~nm}$. The instrument includes a flat Teflon diffuser, interference filters and silicon detectors, and the inside temperature of the instrument is maintained at $40^{\circ} \mathrm{C}$. The instrument is described in detail in Høiskar et al. (2003), including the method to derive daily doses and UV index which is based on Dahlback (1996). The method is mainly the same as that for retrieving UV products from the GUV radiometers and includes calibration against a reference spectroradiometer. The irradiance scale was traceable to NIST via the Swedish Testing and Research Institute (SP) (Johnsen et al., 2002). As described in Lakkala et al. (2005), the quality assurance of the NILU-UV measurements included regular lamp measurements and solar comparisons against a regularly calibrated travelling reference radiometer. The measurement capacity of the channels of the NILU-UV radiometers was found to drift during the measurement period, and the data were corrected for this drift using the results of the solar comparisons by transferring the calibration from the travelling reference to the site radiometer. The yearly comparisons between the travelling reference of the network and the SUV-100 spectroradiometer of NSF in Ushuaia showed differences of less than $5 \%$ between the two instruments. Details about the correction are described in Lakkala et al. (2005, 2018). After the corrections, the combined uncertainty was calculated to be $9.5 \%$ and the expanded uncertainty was $19 \%$ using a coverage factor of 2 for the time period 2000-2008, which is used in this study. Af- ter 2008 the uncertainty of the measurements increased due to severe drift of the channels, and since 2011 the measurements could no longer be used for research and they were stopped.

From the NILU-UV measurements, the average, minimum and maximum erythemal daily doses and the maximum daily UV indices were determined for each day from 1 min averages.

\subsubsection{Total column ozone measurements}

TOC data were gathered from multiple sources. For 20172019, measurements from the GUV radiometers were used. The calculation of TOC is described in Bernhard et al. (2005). It is based on instrument-specific lookup tables and the ratio of irradiances measured at 305 and $340 \mathrm{~nm}$. Pre-calculated lookup tables relate TOC to the SZA and the ratio of the irradiances. They are calculated using the radiative transfer model libRadtran (Mayer and Kylling, 2005) in which site-specific conditions (like altitude, albedo, $\mathrm{O}_{3}$ profile, etc.) are taken into account. Also, the modelled spectra are weighted with the GUV response functions at 305 and $340 \mathrm{~nm}$. Bernhard et al. (2005) validated the method at several sites, including Antarctic sites, and found that the difference between Total Ozone Mapping Spectrometer (TOMS) total ozone and GUV total ozone was within $5 \%$ for SZAs smaller than $75^{\circ}$.

TOC daily averages were calculated from the GUV radiometer measurements, where only observations with SZA $<65^{\circ}$ were used as higher SZA TOC showed a SZA dependency. In Marambio, the period during which the SZA goes below that threshold lasts from the middle of September to the middle of March.

For comparison, level 3 data with $0.25^{\circ}$ resolution from the Ozone Monitoring Instrument (OMI) on board the Aura satellite (Levelt et al., 2018), received through the NASA Giovanni interface (https://giovanni.gsfc.nasa.gov/giovanni/, last access: 14 June 2019), were used. Daily values of the OMI ozone product co-located with the Marambio station $\left(64.125^{\circ} \mathrm{S}, 56.625^{\circ} \mathrm{W}\right.$ for OMI data) were used and the ratio of daily ozone values (OMI / GUV) was calculated. In the majority of the days $(88 \%)$, the ratio falls in the range of $1 \pm 0.05$ (Fig. 2). The median of the ratio OMI / GUV is 1.01, indicating slightly higher values for the OMI data, especially in 2018/2019. There is a small drift between the seasons; the average ratio is 1.00 in 2017/2018 and 1.02 in 2018/2019. The OMI ozone product has shown very good stability over time and a low bias between ground-based Dobson Brewer instruments in the Northern Hemisphere (McPeters et al., 2015). OMI data were used also for other stations included in the study.

Satellite data were also used for comparing TOC values from 2017-2019 to the period 2000-2008 and to explain the changes in erythemal UV doses and maximum UVI values. For the period 2000-2004, version 8 TOC data from 


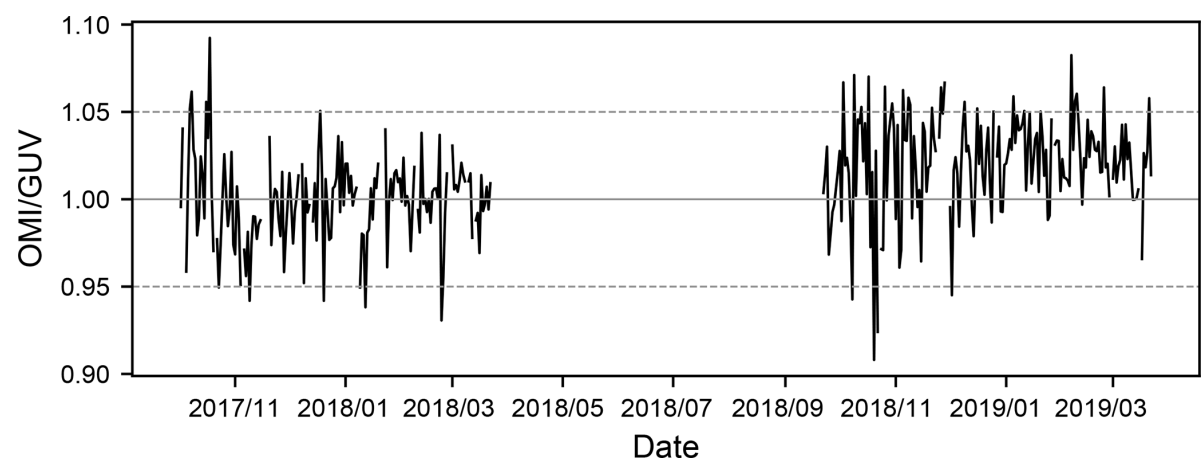

Figure 2. The ratio of OMI / GUV daily TOC from 2017-2019. For GUV daily averages, measurements with SZA below $65^{\circ}$ were used.

Earth Probe (EP) TOMS were used. This dataset is available on a $1^{\circ} \times 1.25^{\circ}$ grid and was taken for coordinates $64.5^{\circ} \mathrm{S}$, $56.875^{\circ} \mathrm{W}$, which represent the Marambio station. For 20052008, OMI data were used, as described in the previous paragraph. The difference in the location between TOMS and $\mathrm{OMI}$ is due to the different resolution. The good agreement between the two instruments has been presented by Antón et al. (2010), who found an average difference of $0.6 \%$ (with standard deviation (SD) less than $3 \%$ ).

\subsubsection{Proxy data}

For the interpretation of changes in the UV irradiance in Marambio, data for different factors affecting UV radiation and ozone in the atmosphere were collected. These data includes polar vortex information, clouds, aerosols and albedo.

- Polar vortex. To investigate the influence of the polar vortex on our observations, the location of the Marambio station with reference to the polar vortex was determined for the seasons 2017/2018 and 2018/2019. For this, the modified potential vorticity, scaled to $475 \mathrm{~K}$, from ERA-Interim data was used (Lait, 1994). Similar to Lakkala et al. (2018), the station was considered to be inside the polar vortex when the value was smaller than -36 . The same method was used for gathering the information about polar vortex for the other stations.

- Clouds. Cloud data used in this study are from observations performed by surface meteorological observers (SMOs) in Marambio. Cloud observations are part of the manual meteorological observations protocol. During hourly observations, the SMO performs a visual inspection of the sky, defining the cloud type and the cloud cover in oktas. The cloud type is further connected with the cloud altitude, which is divided into low-, mediumand high-level clouds. The total amount of clouds in these three levels is also visually estimated according to a standardized protocol. In Marambio, because of the location and the lack of obstacles, it is possible to view the entire sky. This allows the SMO to detect different types of clouds at different heights if the low cloud cover allows it. However, occasionally, the arrival of fog, a heavy snowstorm or another exceptional high concentration event may prevent the observation of the sky above the surface.

The cloud meteorological observations in Marambio follow the protocols recommended by the World Meteorological Organization (WMO) based on the cloud atlas (WMO, 2017), which was developed and is governed by the international community. Therefore, it constitutes the frame of reference for all visual cloud meteorological observations by surface meteorological observers and is an official meteorological observation method.

From the cloud observations dataset, daily and monthly averages were calculated for total and low cloud cover.

- Aerosols. To describe aerosol characteristics, the aerosol optical depth (AOD) at $550 \mathrm{~nm}$ from the Collection 6.1 (Levy et al., 2018) L3 monthly product (MYD08_M3) from the Moderate Resolution Imaging Spectroradiometer (MODIS) sensor on the Aqua satellite was used. Aqua is a polar-orbiting satellite with an Equator crossing around 13:30 LT (local time). In MYD08_M3, all statistics are sorted into $1^{\circ} \times 1^{\circ}$ cells on an equalangle global grid. The Monthly L3 product is computed from the complete set of daily files that span a particular month. Aerosol-related parameters in the monthly product required three valid daily (D3) grid cells to populate the monthly aggregate. Aqua MODIS has a good performance among all AOD monthly products with small overestimation overall (Sogacheva et al., 2020; Wei et al., 2019).

- Albedo. The continuous surface UV albedo measurements started in Marambio in 2013, as an ArgentinianFinnish scientific cooperation. The albedo is measured at a fixed height of approximately $2 \mathrm{~m}$ from the ground using two broadband SL501A (SolarLight Co.) radiometers. The radiometers make hemispherical measurements of the incoming irradiance weighted with the action spectrum for UV-induced erythema (McKinlay 
and Diffey, 1987), which also has a contribution from the UVA. One sensor is installed to face upwards to measure downwelling global erythemal UV irradiance, including both direct and diffuse components, and the other one looks downwards to measure upwelling outgoing hemispherically reflected global diffuse erythemal UV irradiance. The data are recorded at $1 \mathrm{~min}$ intervals. The albedo is then calculated as the ratio of upwelling to downwelling erythemally weighted UV irradiance. The monthly averages of daily noon UV albedo were calculated from these local albedo data. As a best practice, sensors with similar spectral and cosine responses are used (more details in Meinander et al., 2008). The sensors are temperature controlled. In the data file, one column contains the sensor temperature recorded every minute. As SL501A measurements can be temperature affected, temperature records are used for the QA/QC (quality assurance and quality control) online monitoring of the measurements. The Finnish Radiation and Nucleation Safety Authority (STUK) determines the calibration factor for each SL501 sensor, which is used to calibrate the measurement data. The official SL501A trace is to NIST (Lakkala et al., 2018). Via the primary calibration lamp, the measurements are traceable also to the National Standard Laboratory MIKES, Aalto University (HUT), Finland. The difference in calibration coefficients using NIST and MIKES has been found to be less than $2 \%$, and a comparison of spectral UV irradiance scales maintained by NIST, PTB (Physikalisch-Technische Bundesanstalt) and Aalto University shows that there are no major differences (Jokela et al., 2000). For these calibrated, spectrally characterized and temperature controlled sensor data, effects of degradation are not corrected for. Changes in the stability of the sensors between the preand post-calibrations remain to be determined. However, it can be noted that any similar temporal degradation of the two SL501A sensors, as measured in percentages, would be compensated when the ratio of the signals is calculated for albedo. Hence, in post-calibrated data, it will be essential to study whether the degradation of one instrument is different from that of the other one. In general, when use is made of albedo measurements by SL501 radiometers with similar spectral responses, errors due to differences in the sensors are expected to be less than $1 \%$ (WMO, 1997). As described in Hülsen and Gröbner (2007), the typical total uncertainty for SL501 instruments is $1.7 \%-4.3 \%$.

\subsection{Princess Elisabeth Antarctica station in Utsteinen}

The Belgian Princess Elisabeth Antarctica station is located on the granite ridge of the Utsteinen Nunatak in Dronning Maud Land, East Antarctica (Herenz et al., 2019; Pattyn et al., 2010) (see Fig. 1). It is located about $200 \mathrm{~km}$ inland from the Antarctic coast and lies north of the Sør Rondane mountain range. The station lies in the escarpment zone between the Antarctic inland plateau and the coast, where it experiences the influence of both synoptic weather systems and katabatic winds (Gorodetskaya et al., 2013). It has been designed as a zero emission station that is inhabited from November until the end of February, with remote access to instruments during winter.

UV spectral measurements at the station are provided by the double-monochromator Brewer spectrophotometer \#100 of the Royal Meteorological Institute of Belgium (RMI). Accurate spectral profiles of UV radiation in the $290-325 \mathrm{~nm}$ wavelength range are measured. The raw counts are converted to counts per second and corrected for instrument dead time, dark count and temperature. The corrected raw count rates are then divided by the instrument response values. This responsivity is obtained by measuring the response of the Brewer to a source with known radiation (tungsten halogen lamps with a calibration certificate). The spectral erythemal solar UV irradiance, $E_{\text {ery }, \lambda}$ (in $\mathrm{W} \mathrm{m}^{-2} \mathrm{~nm}^{-1}$ ), is calculated by multiplying $E_{\lambda}$ with the appropriate weighting values at each wavelength (CIE action spectrum). UVI values are derived according the method described above. Lamp tests with standard $50 \mathrm{~W}$ lamps are performed during calibration campaigns at Uccle (Belgium). Changes in the stability of the instrument between the two calibrations (in 2010 and 2014) remained within $10 \%$. Note, that the Brewer spectrophotometer is only operated when the station is inhabited November to February).

Noon UVI values used in this study are from measurements conducted by the Royal Belgian Institute for Space Aeronomy (BIRA-IASB) using a pyranometer, manufactured by EKO Instruments (Japan), for UVB (model MS212W, 280-315 nm). The UVB pyranometer, equipped with a quartz dome and stabilized temperature, provides global irradiance measurements that are averaged every minute. The raw data (in volts) are converted into units of watt per square metre $\left(\mathrm{W} \mathrm{m}^{-2}\right)$ using the factory calibration coefficient and a procedure to consider the deviation of the angular response of the instrument to the ideal cosine response. Calibrated data are converted into UVI. The uncertainty of UVI reaches up to $10 \%$, due to trends in the calibration and the absence of angular correction.

\subsection{Troll station}

The Atmospheric Observatory at Troll is operated by the Norwegian Institute for Air Research (NILU) at Trollhaugen. The observatory is located approximately $1 \mathrm{~km}$ east of the Troll research station in the Jutulsessen nunatak area, Queen Maud Land, about $235 \mathrm{~km}$ from the coast and $1553 \mathrm{~m}$ a.s.l. (Fig. 1). The station is unperturbed by local activity and has continuous year-round monitoring in Antarctica.

UV products are calculated from measurements of a NILU-UV instrument (serial number 005) with five UV 
channels $(302,312,320,340$ and $380 \mathrm{~nm})$ and FWHM of about $10 \mathrm{~nm}$. The instrument records data with $1 \mathrm{~min}$ time resolution. The relative spectral response function was calculated at the Norwegian Radiation and Nuclear Safety Authority. For absolute calibration, the Sun is used as a light source and irradiance is measured by a reference radiometer at the same time and location as NILU-UV. Once every month, a relative calibration takes place at the station to determine the drift factor and compensate for the degradation of the optical components (Sztipanov et al., 2020).

\subsection{Palmer Station, McMurdo Station and South Pole Station}

Palmer Station, McMurdo Station and South Pole Station (see Fig. 1 for locations) are all part of the United States Antarctic UV Network and the data and information about the sites were received through the network website (https://esrl.noaa.gov/gmd/grad/antuv/, last access: 16 January 2020).

Out of all the selected stations, Palmer Station is the closest to Marambio. It is situated on Ansver Island just outside the Antarctic Circle. (Information from https://esrl.noaa.gov/ gmd/grad/antuv/Palmer.jsp, last access: 13 June 2019).

McMurdo Station is located on the southern tip of Ross Island. The solar season lasts from August to April, but the station is opened all-year round. (information from https://esrl. noaa.gov/gmd/grad/antuv/McMurdo.jsp, last access: 13 June 2019).

South Pole Station is located at the geographic South Pole. The solar season lasts there from September to March. The annual average temperature at the pole is $-49^{\circ} \mathrm{C}$. The conditions are quite different from all the other stations as there is almost no diurnal change in SZA. The meteorological conditions at the station are stable. There is also low cloud cover, constant snow and very low air pollutant levels. (information from https://esrl.noaa.gov/gmd/grad/antuv/ SouthPole.jsp, last access: 13 June 2019).

Version 2 data from the National Oceanic and Atmospheric Administration (NOAA) Antarctic UV data repository were used for Palmer Station, McMurdo Station and South Pole Station. It is the newest release that has higher accuracy than previous versions and has been corrected for cosine error (Bernhard et al., 2004). UVI values from "Database 3" were used. All three stations use the NSF SUV100 instrument, manufactured by Biospherical Instruments Inc. The uncertainty of biologically relevant UV irradiance is approximately $6 \%$ (Bernhard et al., 2004). The instruments are calibrated periodically using a $200 \mathrm{~W}$ tungsten halogen standard lamp, traceable to NIST.
Table 2. Monthly averages of daily erythemal doses $\left(\mathrm{kJ} \mathrm{m}^{-2}\right)$ from September to March with SD (in brackets) for the seasons 2017/2018 and 2018/2019. Higher values in each month are in bold. For September 2017, $13 \mathrm{~d}$ were available, for the rest of the months at least $25 \mathrm{~d}$ were included. For comparison, monthly averages with SD for the years 2000-2008 are included in the third column and discussed in Sect. 3.2.

\begin{tabular}{llll}
\hline & $2017 / 2018$ & $2018 / 2019$ & $2000-2008$ \\
\hline September & $0.61(0.21)$ & $\mathbf{1 . 0 2}(0.58)$ & $1.05(0.65)$ \\
October & $2.16(0.78)$ & $\mathbf{3 . 0 2}(1.00)$ & $2.21(0.97)$ \\
November & $2.43(0.48)$ & $\mathbf{2 . 8 3}(0.96)$ & $2.91(1.15)$ \\
December & $2.50(0.70)$ & $\mathbf{3 . 3 8}(1.05)$ & $3.23(1.00)$ \\
January & $2.58(0.89)$ & $\mathbf{3 . 1 3}(1.06)$ & $2.93(0.97)$ \\
February & $2.04(0.67)$ & $\mathbf{2 . 1 4}(0.81)$ & $1.87(0.70)$ \\
March & $0.82(0.33)$ & $\mathbf{1 . 0 8}(0.61)$ & $0.82(0.35)$ \\
\hline
\end{tabular}

\section{Results}

\subsection{Characteristics of UV radiation in Marambio, 2017-2019}

To describe the UV radiation levels and compare the past two seasons, daily erythemal UV doses in Marambio were calculated (Fig. 3). The UV irradiances manifest two peaks - one during annual destruction of $\mathrm{O}_{3}$ (the so-called ozone hole) during the local spring (September-November) and the other one in the summer (December-January) when noon SZA is the lowest. These periods with high doses were present in both seasons: 2017/2018 and 2018/2019. The largest variations of the UV irradiance occur also during these seasons (spring and early summer). The standard deviation of the erythemal daily dose in October 2017 and 2018 was $0.99 \mathrm{~kJ} \mathrm{~m}^{-2}$ and in January 2018 and 2019 was $1.02 \mathrm{~kJ} \mathrm{~m}^{-2}$; in September and March it is around $0.5 \mathrm{~kJ} \mathrm{~m}^{-2}$. There is a visible difference between the measured UV irradiances in 2017/2018 and 2018/2019 (Fig. 3). In 2017/2018 the average daily erythemal dose from September-March was $1.88 \mathrm{~kJ} \mathrm{~m}^{-2}$, while in the next season it was $23 \%$ larger $\left(2.37 \mathrm{~kJ} \mathrm{~m}^{-2}\right)$, and the monthly average of daily doses was lower in each month during 2017/2018 compared to the corresponding month in 2018/2019 (Table 2).

The maximum daily erythemal doses measured in seasons $2017 / 2018$ and 2018/2019 were $4.17 \mathrm{~kJ} \mathrm{~m}^{-2}$ (on 7 January 2018 ) and $5.40 \mathrm{~kJ} \mathrm{~m}^{-2}$ (on 4 January 2019), respectively, i.e. a difference of more than $25 \%$. The maximum daily dose of 2017/2018 was exceeded on 20 of the days (during the months of October 2018 to January 2019) in 2018/2019, which shows that daily doses were systematically larger in that period than in the year before.

The variation of the daily maximum UVI closely followed that of the daily erythemal doses in both seasons (Fig. 4). In season 2017/2018, the daily maximum UVI values were overall lower than 6 , with high values (UVI 6-7, accord- 


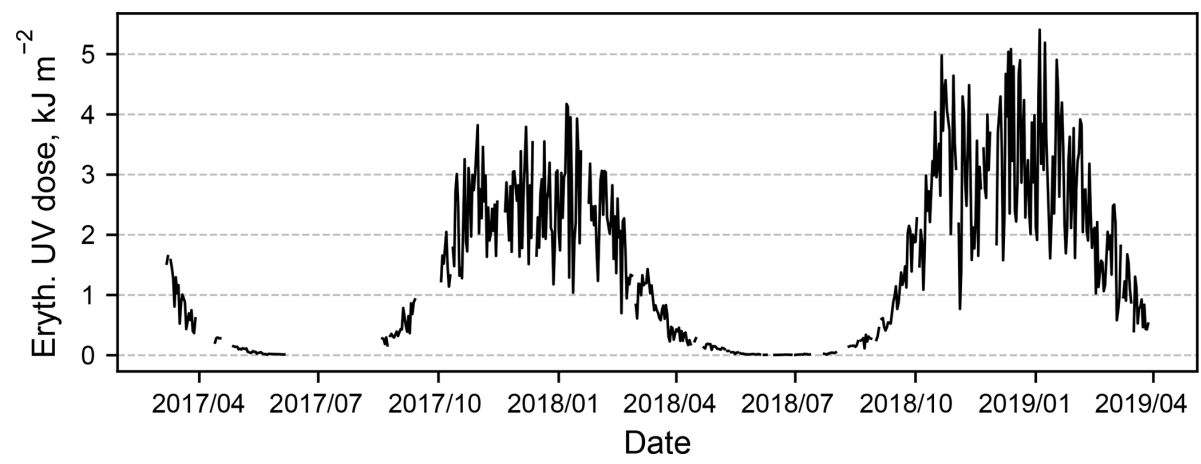

Figure 3. Daily erythemal UV doses in Marambio from March 2017 to March 2019.

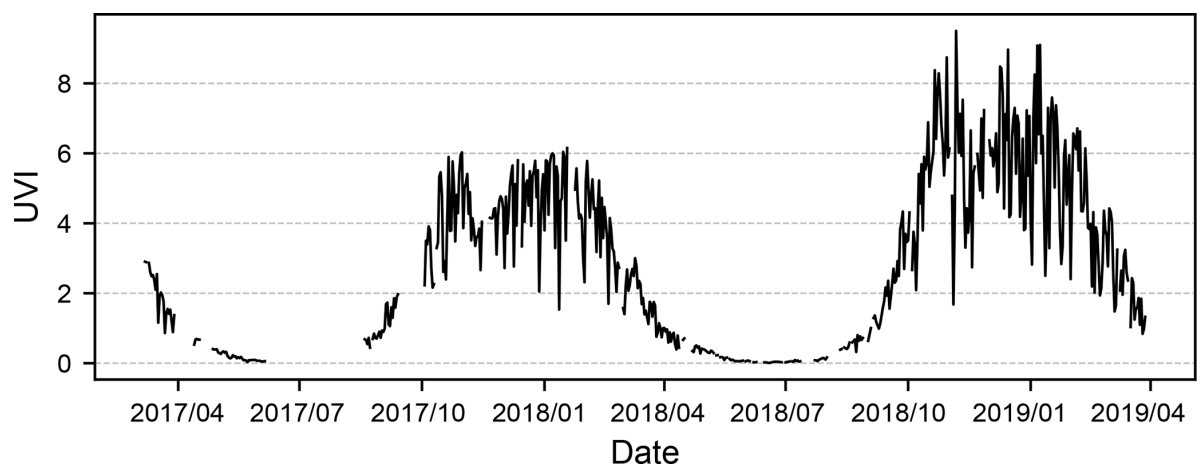

Figure 4. Daily maximum UV indices in Marambio from March 2017 to March 2019.

ing to the WHO (World Health Organization) categorization; WHO, 2002), on only $3 \mathrm{~d}$. The maximum value was 6.2 (measured on 18 January 2018). In the second season, the maximum UVI was much higher, 9.5 (6 November 2018), and there were $59 \mathrm{~d}$ on which the UVI exceeded 6 . Out of those, $10 \mathrm{~d}$ had very high values (UVI 8-10; WHO, 2002).

Variations in factors affecting UV irradiance at ground level must be the reason for the considerable differences between the two seasons. The most important factors influencing UV are cloud cover and $\mathrm{O}_{3}$ (Kerr, 2005; Seckmeyer et al., 1996). Also, albedo and aerosol can cause the variations in erythemal UV.

The monthly averaged cloud cover for the months during which the solar irradiance is the highest in Marambio (October-February) is presented in Table 3. In 2017/2018, cloud cover in October, December and January was higher than in 2018/2019, with the largest difference in October (1.1 oktas), while in November and February the cloud cover was lower by 1 and 0.8 oktas, respectively. As the effect of clouds on UV irradiance depends on the type of cloud (Lopez et al., 2009), the same calculations of monthly averages and comparison between months were done for low clouds, but the results were very similar with respect to differences between the seasons. As clouds mainly attenuate radiation, smaller cloud cover but similar SZA results in more UV radiation reaching the ground. This means that, for our dataset, cloud cover can qualitatively explain part of the lower UV values observed in October, December and January in 2017/2018 compared to those in 2018/2019. In November and February the average cloud cover is lower in $2017 / 2018$ compared to $2018 / 2019$, meaning there are other factors causing the lower UV doses in 2017/2018 during these months in comparison to 2018/2019.

The daily average TOC values are plotted in Fig. 5. The TOC value averaged over the season 2017/2018 was 297 DU (SD 49 DU, Dobson units) with a minimum of $152 \mathrm{DU}$ and a maximum of 386 DU. In 2018/2019, the average was $12 \%$ smaller, 263 DU (SD 53 DU), with a minimum of $131 \mathrm{DU}$ and a maximum of $367 \mathrm{DU}$. The TOC value in Antarctica is influenced by the location of the polar vortex: inside the polar vortex, TOC values are generally lower. For estimating whether the Marambio station was inside or outside the polar vortex, potential vorticity analysis was carried out (see Sect. 2.1.3). The potential vorticity was lower than the chosen limit of -36 during a total of $130 \mathrm{~d}$ in the season 2017/2018 and $134 \mathrm{~d}$ in 2018/2019. In spring, when the ozone hole is present, Marambio was inside the polar vortex for $68 \mathrm{~d}$ during 2017/2018 and $83 \mathrm{~d}$ during 2018/2019. The first day since September 2018, when the potential vorticity was not lower than -36 , was 5 November. In 2017, the situation was much less stable with several days (both in September and October) on which the Marambio station was 
Table 3. Monthly-average total cloud cover (oktas), TOC (DU), AOD at $550 \mathrm{~nm}$ and albedo with SD in the parentheses for 5 months in the seasons 2017/2018 and 2018/2019. "NA" denotes that data are not available.

\begin{tabular}{lrr|rr|rr|rr}
\hline & \multicolumn{2}{c}{ Cloud cover (oktas) } & \multicolumn{2}{c|}{ TOC (DU) } & \multicolumn{2}{c|}{ AOD } & \multicolumn{2}{c}{ Albedo } \\
\cline { 2 - 9 } & $2017 / 2018$ & $2018 / 2019$ & $2017 / 2018$ & $2018 / 2019$ & $2017 / 2018$ & $2018 / 2019$ & $2017 / 2018$ & $2018 / 2019$ \\
\hline October & $5.9(2.1)$ & $4.8(1.9)$ & $234(61)$ & $191(26)$ & NA & 0.155 & $0.3(0.1)$ & NA \\
November & $5.1(2.1)$ & $6.1(1.7)$ & $336(54)$ & $275(65)$ & 0.097 & 0.112 & $0.1(0.1)$ & $0.2(0.2)$ \\
December & $6.6(1.2)$ & $5.9(1.8)$ & $321(18)$ & $309(18)$ & 0.072 & 0.089 & $0.2(0.1)$ & $0.2(0.2)$ \\
January & $6.9(1.5)$ & $6.7(1.5)$ & $307(12)$ & $290(13)$ & 0.076 & 0.089 & $0.2(0.1)$ & NA \\
February & $6.2(1.2)$ & $7.0(1.5)$ & $301(15)$ & $278(21)$ & 0.136 & 0.096 & $0.2(0.2)$ & $0.4(0.1)$ \\
\hline
\end{tabular}

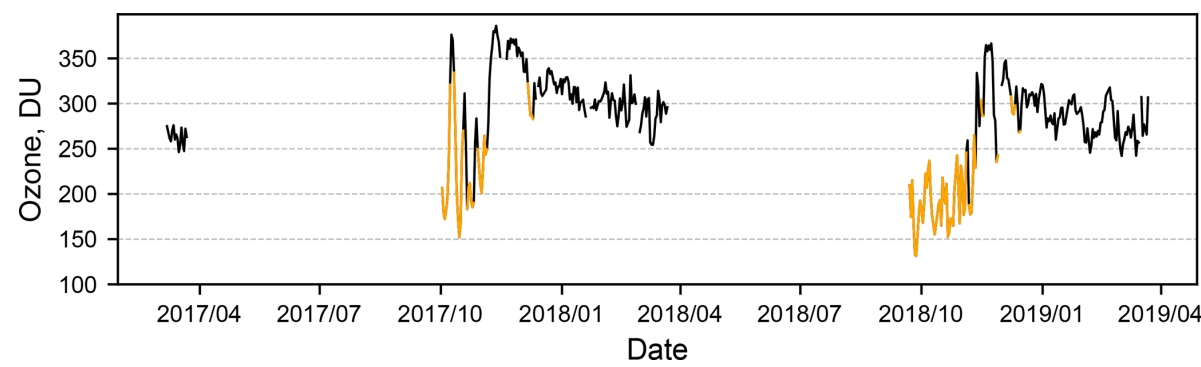

Figure 5. Daily average TOC at Marambio calculated from GUV measurements with SZA $<65^{\circ}$ (2017-2019). Days during which the station was inside the polar vortex (vorticity $<-36$ ) are in orange.

outside the polar vortex and more ozone was present in the atmospheric column above.

The monthly averages are lower for each month in $2018 / 2019$ and the disparity is especially large in October and November, 43 and 61 DU, respectively (Table 3). These are the months during which the ozone hole occurs and the thickness of the ozone layer is most variable.

For describing the effect of $\mathrm{O}_{3}$ on UV irradiance, the RAF with a value of 1.2 has been used. The expected changes in average daily erythemal dose due to a decrease in average TOC between the seasons 2017/2018 and 2018/2019 was calculated for each month from October to February and compared to the measured changes (Fig. 6). The results were similar when using the power-law relationship for calculating RAF (McKenzie et al., 2011) (Sect. 2) for larger changes in $\mathrm{O}_{3}$. In November and February the increase in monthly-average UV from 2017/2018 to 2018/2019 is caused by ozone, but, due to higher cloud cover in the second season, the increase is less than calculated solely using RAF. In October, more than half of the increase can be explained by the decrease in TOC and the rest is due to the larger cloud cover in 2018/2019 (1.1 oktas), which is the largest difference in monthly averages for those two seasons. In December and January, less than one-third of the increase in average erythemal dose is explained by ozone and the rest of the change is due to other factors. In both months, the average cloud cover is lower in 2018/2019 than in 2017/2018 (0.7 and 0.2 oktas, respectively). In January, the average difference in cloud cover is small as is the difference in average TOC (17 DU). However, it is important to note the timing when those dif-

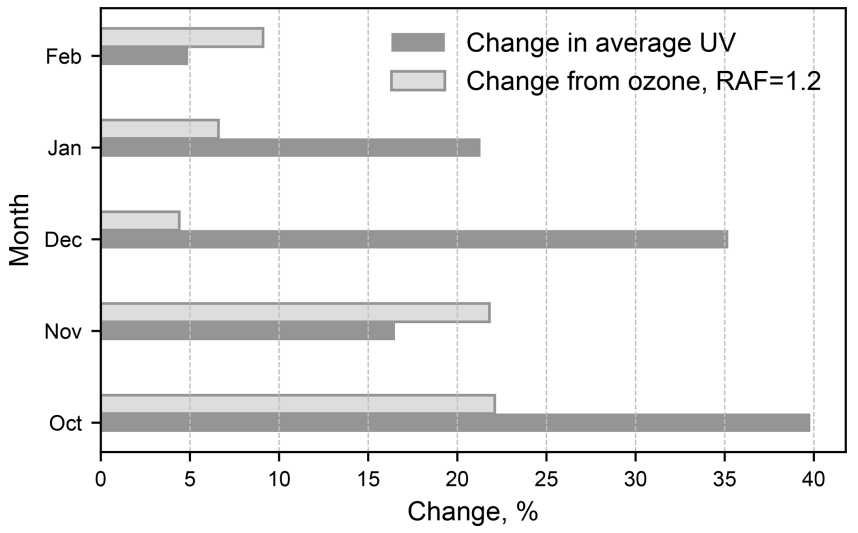

Figure 6. Change in average daily erythemal dose between the seasons 2017/2018 to 2018/2019 for each of the months from October to February (dark grey) and expected changes due to decrease in average TOC using $\mathrm{RAF}=1.2$ (light grey)

ferences occur. The TOC is lower from 2 to 18 January 2019 compared to the same period in 2018. In the first half of January the noon SZA is lower than in the second half. In the second half of January 2019, the cloud cover was lower there were $5 \mathrm{~d}$ with daily average cloud cover smaller than 5 ; at the same time in 2018 there were none. So even though the monthly mean values are similar, there are day-to-day variations and the factors causing higher daily doses in 2019 are different during different days.

Aerosol concentrations in Marambio are low and the aerosol mixture consists mainly of sulfate, sea salt and crustal 
mineral components (Asmi et al., 2018). The AOD monthly averages are lower than 0.2 in both years (Table 3). The differences between the different months in 2017/2018 and 2018/2019 are within the known uncertainty (around $0.05+$ $20 \%$ over land and $0.03+15 \%$ over ocean; Levy et al., 2013). This means that regarding AOD, no significant difference was found between the two time periods.

Albedo, which also affects the UV irradiance measured in Marambio, mainly depends on snow cover. Unfortunately, albedo measurements are not available at Marambio for all months in 2018/2019. The data that are available show a slightly higher monthly average for the daily noon albedo in November 2018 compared to November 2017 and in February 2019 compared to February 2018; the differences are 0.1 and 0.2 , respectively. Higher average albedo will lead to higher recorded UV doses, which supports our finding of higher UV levels in 2018/2019 compared to 2017/2018. Snow on the surface has been shown to increase the monthly erythemal doses by more than $20 \%$ (Kylling et al., 2000). These authors report that clouds reduce the monthly erythemal doses by $20 \%-40 \%$. The averages in the presented data were calculated from 21-30 daily noon albedo values per month except for October 2017, when only eight values were available. Hence, it can be concluded that these data showed a slight year-to-year differences in surface UV albedo for November and February and no difference for December. October and January could not be compared due to missing data. Albedo changes are likely connected with changes in surface conditions (snow, no snow or impurities on snow). Our albedo data demonstrate the need for continuous measurements of albedo and UV doses to detect seasonal and year-to-year variability and long-term changes and trends. They also indicate a further need to study the reasons behind the observed albedo changes from one season to another.

Daily doses of UVA $(315-400 \mathrm{~nm})$ radiation were also somewhat higher in 2018/2019 than in the previous year, but the difference was not as large as for erythemal radiation. Average daily UVA doses from October to February in $2017 / 2018$ were $0.78,1.18,1.04,1.04$ and $0.91 \mathrm{MJ} \mathrm{m}^{-2}$; in $2018 / 2019$ these numbers were $0.89,1.04,1.24,1.08$ and $0.79 \mathrm{MJ} \mathrm{m}^{-2}$ (Lakkala et al., 2020). The different behaviour of erythemal and UVA radiation shows the importance of $\mathrm{O}_{3}$ in causing the significant differences observed between the two seasons for erythemal radiation and UVI, as the UVA is not affected by $\mathrm{O}_{3}$ but mainly by cloud cover and surface albedo.

Proxy data together with UVA data show that the cause behind low erythemal irradiance in Marambio is mainly from a combination of the influences of $\mathrm{O}_{3}$ and clouds, as no conclusions can be drawn from the albedo data. In October over half of the difference in UV can be explained by $\mathrm{O}_{3}$, while the other half is explained by the higher cloud cover in 2017. In November and February the lower cloud cover in 2017/2018 reduced the effect of $\mathrm{O}_{3}$ and in January and December most of the difference is caused by differences in cloud cover.

\subsection{Comparison with previous (2000-2008) measurements in Marambio}

The past two UV seasons in Marambio have not been extreme, although there were periods when the erythemal daily doses and maximum UVI were noticeably different from the averages in the period 2000-2008. In general, daily erythemal doses measured during 2017-2019 fall in the range of the long-term fluctuations of daily doses measured between 2000 and 2008 (Fig. 7). In the season 2017/2018 though, there was a long period from spring until the end of the summer ( $57 \mathrm{~d}$ in October-December), when daily doses were mostly below the long-term daily average. On 16 of these days, the values were even below the long-term minimum. The monthly averages of daily doses in that season were below the long-term values from October to January (Table 2) with differences from $2.3 \%$ to $25.5 \%$. The same is true for September, but only $13 \mathrm{~d}$ of measurements were available for calculating monthly averages. In spring 2018, there was a longer period (13 October-1 November), when the daily doses were continuously above the long-term average, and in addition they were above the average for half of the days in November and December. The monthly-average daily erythemal dose in October exceeded the long-term average with more than $0.8 \mathrm{~kJ} \mathrm{~m}^{-2}$. Monthly averaged daily doses were higher than the long-term values also from December to March. In addition, there were several days in spring 2018 (five in October and five in December) when the daily doses exceeded the long-term maximum, although the highest erythemal daily dose recorded during 2000-2008 was over $6.9 \mathrm{~kJ} \mathrm{~m}^{-2}$ (19 November 2007), and none of the daily doses reached that high in recent seasons.

For the daily maximum UVI, the situation was similar to that of the daily erythemal doses (Fig. 8). The maximum value recorded in 2000-2008 was 12, but in 2017-2019 such high values were not reached because the combination of low TOC together with low cloud cover causing the high TOC values in 2000-2008 did not occur in 2017-2019. Longterm daily maximum values were exceeded on $19 \mathrm{~d}$ during 2017/2018. The majority of these days were in April and May and none in the spring. In 2018/2019, there were 30 such days -6 in spring, including the day with the record value of 9.5. During a large part of 2017/2018, UVI was below the long-term daily maximum mean $(127 \mathrm{~d})$. On $43 \mathrm{~d}$ UVI values even went below the long-term minimum. In $2018 / 2019$, the number of days during which the UVI was below the long-term daily maximum mean and below the long-term minimum was 110 and 26, respectively.

The sharp drop in maximum UVI values (from 5.4 to 2.6 in $10 \mathrm{~d}$ ) in November 2017 is coincident with the abrupt rise in TOC (from 243 to $368 \mathrm{DU}$ for the same period) that at its peak exceeded even the long-term variation limits. The general TOC level stayed high until the end of the summer in March 2018 compared to the measurements from 2000-2008 (Fig. 9). Daily TOC was higher than the long-term maximum 


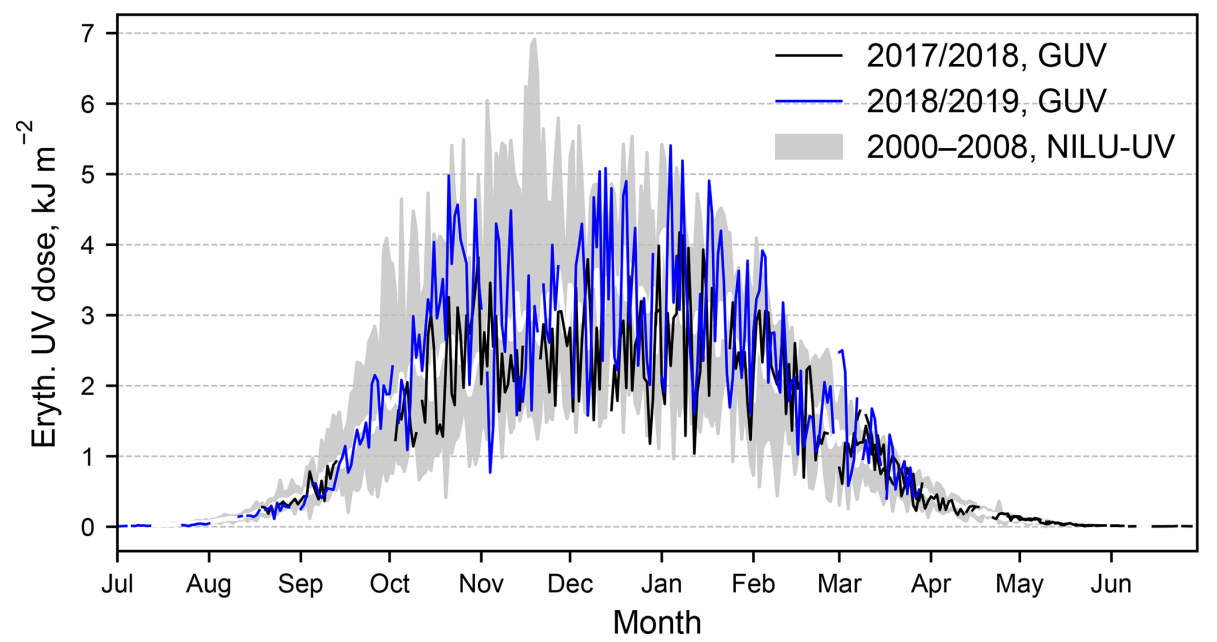

Figure 7. Comparison of daily erythemal UV doses from GUV measurements in Marambio in seasons 2017/2018 (black line) and 2018/2019 (blue line) with long-term measurements (2000-2008). The white line is the long-term (2000-2008) mean, and the grey area is set between long-term maxima and minima for each day.

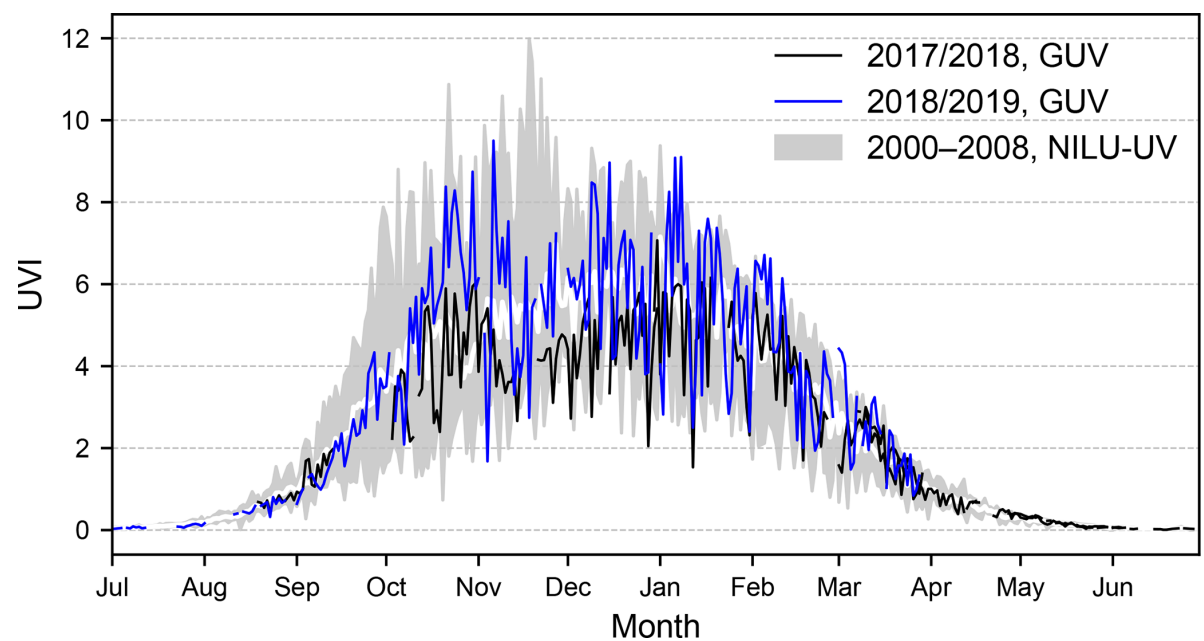

Figure 8. Comparison of daily maximum UVI from GUV measurements in Marambio in the seasons 2017/2018 (black line) and 2018/2019 (blue line) with long-term measurements (2000-2008). The white line is the historical mean (2000-2008), and the grey area is set between historic maxima and minima of maximum UVI for each day.

on 54 out of $162 \mathrm{~d}$ in the season $2017 / 2018$, and there is only $1 \mathrm{~d}$ (31 October 2017) when the TOC value was lower than the long-term minimum. In the next season, there were only $14 \mathrm{~d}$ when the maximum values were exceeded and $9 \mathrm{~d}$ when new daily minima were set. The results from the analysis of TOC data are in good agreement with the recent recorded UV levels, when considering the negative correlation of these two values.

Long-term averages of cloud cover in Marambio show an annual cycle for both total and low cloud cover. The total cloud cover was the lowest during July and August, when averages were smaller than 4.5 oktas, and highest during summer, in December and January, where they were larger than 6.1 oktas. This pattern was also present in the seasons of
2017/2018 and 2018/2019 (Table 3). Compared to the 20002008 averages, in 2017/2018 the cloud cover was slightly higher than the average for all months between October and February, with the exception of November, when cloud cover was about 1 okta smaller. Higher than average cloud cover contributes to the lower than average daily erythemal doses. In 2018/2019, the average cloud cover in November and December was similar to the long-term average, whereas in October the cloud cover was smaller and during January and February the cloud cover was larger than the average. 


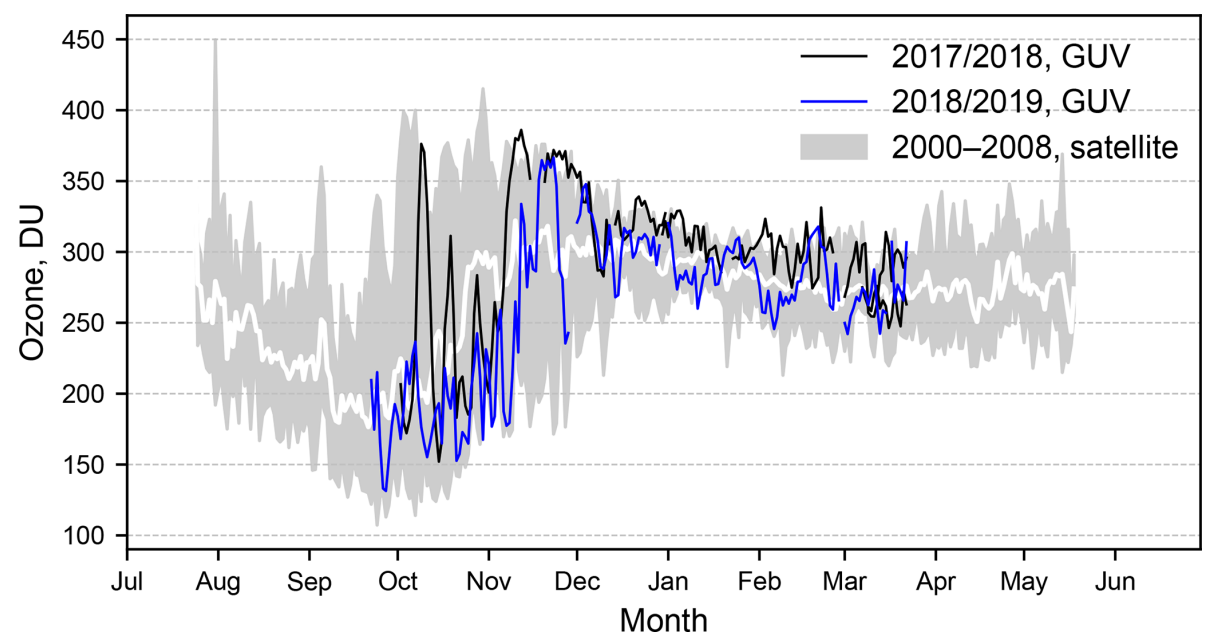

Figure 9. Comparison of TOC calculated from GUV in Marambio in seasons 2017/2018 (black line) and 2018/2019 (blue line) with longterm measurements (2000-2008) from satellites. The white line is the long-term daily average (2000-2008), and the grey area is the region between the period's daily maxima and minima.

\subsection{Comparison of Marambio measurements to other stations}

As shown in Sect. 3.1, Marambio manifested two very different seasons - in 2017/2018 there was less UV radiation than in 2018/2019 and the daily erythemal doses and UVI were often below long-term averages. Including data from other Antarctic stations gives an opportunity for us to compare these results and to decide on whether the same conclusions can be made in other parts of the continent.

First, the differences between seasons 2017/2018 and 2018/2019 were looked at. These data are available for all the included stations (Fig. 10). Higher values in spring 2018 compared to 2017 have been measured at each station, except in Utsteinen from which no measurements are available for spring 2017. For example at South Pole Station, where recorded UVI is the lowest, the maximum UVI was 1.9 during October-November in 2017 and 2.9 in 2018. In 2018 the mean UVI for October-November was also higher (1.5; in 2017 it was 1.0). For October and November, the mean and maximum values were higher for every station (except for Utsteinen due to lack of measurements). The peaks in spring are mainly caused by low TOC during the ozone hole event. The TOC values were higher for most of the spring in each station (Fig. 10), and there were several days when much larger TOC values were recorded in 2017/2018 compared to $2018 / 2019$, with differences of more than $100 \mathrm{DU}$. Utsteinen and Troll stayed inside the polar vortex until 22 and 21 November 2018, respectively, and during some isolated days in the following week. In 2017, these stations were outside the polar vortex by 15 and 13 November, respectively. The earlier disappearance of the polar vortex in 2017 compared to 2018 was also recorded in Palmer Station and McMurdo Station. Palmer Station was for the first time outside the vortex on 9 October 2017, and on 11 November 2018; the corresponding dates for McMurdo Station were 28 October 2017, and 7 December 2018.

Compared to long-term variations and averages from the measurements in 2000-2008, irradiances in Marambio in 2017/2018 were below the average value for the end of spring and most of the summer. This kind of comparison was also done using data from the three American stations - Palmer Station, McMurdo Station and South Pole Station. All of these stations had UVI data available for 20002008 (Fig. 10). Out of these stations, Palmer is the closest to Marambio - roughly $350 \mathrm{~km}$ away and almost at the same latitude. The maximum UVI in Palmer Station was 7.9 for the 2017/2018 season and 11.6 for the long-term time series. With respect to long-term measurements, season 2017/2018 was similar to the one in Marambio. Also in Palmer Station longer periods with UVI lower than the average occurred in spring and summer; from October to December the maximum UVI was smaller than the long-term average during $58 \mathrm{~d}$ and the largest difference was 3 units (14 November 2017). The longest span of days with maximum UVI below the average was from 5-17 November, with a mean difference of 1.5 units. Out of the $58 \mathrm{~d}$, the daily maxima were below the historic minimum value during $10 \mathrm{~d}$. This was also the case for McMurdo Station and South Pole Station: at both stations, average daily maximum UVI values were measured in 2017/2018, which were below those in the period 2000 2008, especially in November and December when also the variation between years was the largest. In McMurdo Station, the longest span of days with below-average maximum UVI between October and December was $27 \mathrm{~d}$ (19 October14 November), while in South Pole Station there were only $7 \mathrm{~d}$ in that period when maximum UVI was above the average. 

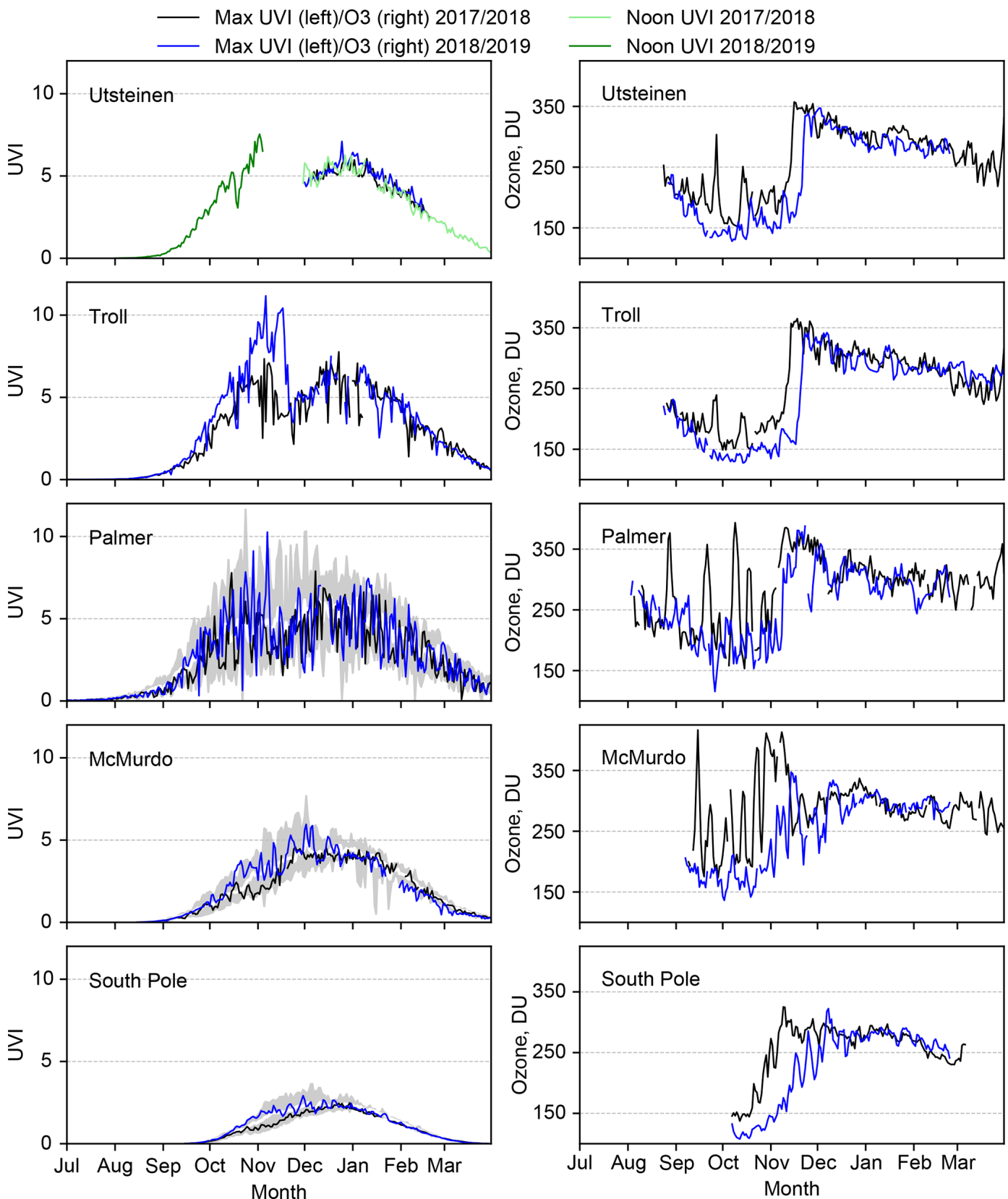

Figure 10. Maximum daily UVI (left) and daily TOC (right) for different Antarctic stations for 2017/2018 (black line) and 2018/2019 (blue line). In the Utsteinen UVI plot, noon UVI values (2017/2018 - light green, 2018/2019 - dark green) have been added to get longer time series. In the plots of UVI in Palmer Station, McMurdo Station and South Pole Station, the long-term (2000-2008) averages (white line) and variations (grey area) have been added.

Based on this comparison, it can be concluded that during the season 2017/2018 the long-term average UV irradiance reaching the surface was lower than in the period 2000-2008 across the Antarctic, and the results obtained for Marambio were not site specific.

\section{Conclusions}

In 2017, UV measurements with a GUV-2511 multichannel radiometer were started in Marambio, Antarctica, by FMI in cooperation with SMN. These measurements were analysed and compared to measurements from 2000-2008 performed with a NILU-UV radiometer at the same station and with data from five other research stations in Antarctica. 
Recent measurements show that in 2017/2018 the average daily erythemal dose from September-March was $23 \%$ lower than the year after, and the monthly-average daily doses were lower for each month with values varying between $4.8 \%$ (February) and $50.3 \%$ (September, where less data were available for 2017). The difference between the two subsequent seasons is also visible from the maximum UVI data - in 2017/2018 there were $3 \mathrm{~d}$ with maximum UVI above 6 units compared to $59 \mathrm{~d}$ in 2018/2019. The daily doses in 2017/2018 were also lower than the long-term average of 2000-2008 (for 57 d from October to December) and a number (16) of new daily minimum values were recorded. In 2018/2019, several new daily maximum values were recorded and the daily doses fluctuated around the longterm average. The lower UV radiation levels in 2017/2018 were not specific for Marambio. Lower than long-term average maximum UVI values were also measured at other stations, such as Palmer Station, McMurdo Station and South Pole Station, during the solar season 2017/2018. Also, the average maximum UVI was lower in 2017/2018 compared to $2018 / 2019$ for each station included in the dataset.

As changes in surface UV irradiance depend mainly on changes in TOC, cloud cover, aerosols and ground albedo, those UV-affecting factors were analysed in this study for Marambio. The computed changes in UV irradiance due to ozone using a RAF value of 1.2 explain the observed changes for November, February and during a large part of October. The role of cloud cover was clearly seen in December and to a lesser degree in October and November, when cloud cover qualitatively explains changes which could not be ascribed to changes in TOC. In this study, the roles of aerosols and albedo are of minor influence, because the variation of these factors in Marambio was small from one year to the other.

The impact of the polar vortex was analysed: in spring 2017, a higher than usual TOC was measured during several days resulting in less UV radiation reaching the ground. During that period, the position of the polar vortex over Marambio alternated frequently. That resulted in less favourable atmospheric conditions for deep $\mathrm{O}_{3}$ depletion during several days, allowing less transmission of UV radiation in the atmospheric column.

Due to the large fluctuation in TOC and the effect of other factors like clouds, the natural variability of UV irradiance is large from year to year. Therefore, it is important to continue the measurements in Antarctica to be able to monitor longterm changes and to determine whether the long awaited recovery of the ozone layer is taking place (WMO, 2018).

Data availability. Data are available upon request from the authors. Data from OMI and TOMS are publicly available through https:// giovanni.gsfc.nasa.gov/giovanni/ (last access: 30 April 2019; Bhartia, 2012). Data for Amundsen-Scott South Pole Station, Palmer Station and McMurdo Station were collected from NOAA Antarctic UV Monitoring Network (Bernhard et al., 2004). Data from
Amundsen-Scott South Pole Station, Palmer Station and McMurdo Station up to 2009 were provided by the NSF UV Monitoring Network (http://uv.biospherical.com; Bernhard et al., 2004).

Author contributions. MA programmed Marambio's GUV data processing, analysed the data and led the article; KL participated in data analysis and contributed to the writing of the article; RS, EA, FN, OM, LS and EJ collected and contributed proxy data for Marambio station and contributed to the writing of the article. VA collected and contributed proxy data; AA and GdL consulted on research and contributed to the writing of the article; $\mathrm{VdB}, \mathrm{AM}, \mathrm{DB}$, TS, LM, and KC collected and contributed data for other stations and contributed to the writing of the article; DG and BVO collected and contributed data for other stations.

Competing interests. The authors declare that they have no conflict of interest.

Acknowledgements. The authors would like to thank the operators of Marambio station for keeping the measurements running and Germar Bernhard from Biospherical Instruments Inc. for calibration of the GUV radiometers. Edith Rodriguez is acknowledged for help with logistics. Hanne Suokanerva and Riika Ylitalo are acknowledged for data dissemination. Patrick Disterhoft is acknowledged for the Amundsen-Scott South Pole Station, Palmer Station and McMurdo Station data. Data from Amundsen-Scott South Pole Station, Palmer Station and McMurdo Station up to 2009 were provided by the NSF UV Monitoring Network, operated by Biospherical Instruments Inc. and funded by the US National Science Foundation's Office of Polar Programs. Data on $\mathrm{O}_{3}$ were collected through the Giovanni online data system, developed and maintained by the NASA GES DISC. We acknowledge the mission scientists and principal investigators, who provided the data used in this research effort. Technical personnel from the Norwegian Polar Institute are responsible for daily maintenance of the instrument.

Financial support. This research has been supported by the State Environmental Fund of the Czech Republic (project no. 03461022 "Monitoring of the ozone layer and UV radiation in Antarctica"), the Ministry of Education, Youth and Sports of the Czech Republic (project LM2015078), the Nordic Centre of Excellence CRAICC, the Academy of Finland's Centres of Excellence programme (project no. 272041), the Ministry for Foreign Affairs of Finland IBA-project (no. PC0TQ4BT-25), EU INTERACT Project (H2020 grant agreement no. 730938), the Academy of Finland NABCEA project (no. 296302), and the Norwegian Ministry of Climate and Environment.

Review statement. This paper was edited by Stelios Kazadzis and reviewed by three anonymous referees. 


\section{References}

Antón, M., Vilaplana, J. M., Kroon, M., Serrano, A., Parias, M., Cancillo, M. L., and de la Morena, B. A.: The Empirically Corrected EP-TOMS Total Ozone Data Against Brewer Measurements at El Arenosillo (Southwestern Spain), IEEE T. Geosci. Remote, 48, 3039-3045, https://doi.org/10.1109/TGRS.2010.2043257, 2010.

Antón, M., Cazorla, A., Mateos, D., Costa, M. J., Olmo, F. J., and Alados-Arboledas, L.: Sensitivity of UV Erythemal Radiation to Total Ozone Changes under Different Sky Conditions: Results for Granada, Spain, Photochem. Photobiol., 92, 215-219, https://doi.org/10.1111/php.12539, 2016.

Asmi, E., Neitola, K., Teinilä, K., Rodriguez, E., Virkkula, A., Backman, J., Bloss, M., Jokela, J., Lihavainen, H., Leeuw, G. de, Paatero, J., Aaltonen, V., Mei, M., Gambarte, G., Copes, G., Albertini, M., Fogwill, G. P., Ferrara, J., Barlasina, M. E., and Sánchez, R.: Primary sources control the variability of aerosol optical properties in the Antarctic Peninsula, Tellus B, 70, 1-16, https://doi.org/10.1080/16000889.2017.1414571, 2018.

Bernhard, G., Booth, C. R., and Ehramjian, J. C.: Version 2 data of the National Science Foundation's Ultraviolet Radiation Monitoring Network: South Pole, J. Geophys. Res.-Atmos., 109, D21207,https://doi.org/10.1029/2004JD004937, 2004 (data available at: http://uv.biospherical.com, last access: 30 April 2019).

Bhartia, P. K.: OMI/Aura TOMS-Like Ozone and Radiative Cloud Fraction L3 1 day 0.25 degree x 0.25 degree V3, NASA Goddard Space Flight Center, Goddard Earth Sciences Data and Information Services Center (GES DISC), https://doi.org/10.5067/Aura/OMI/DATA3002, 2012.

Bernhard, G., Booth, C. R., and Ehramjian, J. C.: Version 2 data of the National Science Foundation's Ultraviolet Radiation Monitoring Network: South Pole, J. Geophys. Res.-Atmos., 109, D21207, https://doi.org/10.1029/2004JD004937, 2004.

Bernhard, G., Booth, C. R., and Ehramjian, J. C.: Real-time ultraviolet and column ozone from multichannel ultraviolet radiometers deployed in the National Science Foundation's ultraviolet monitoring network, Opt. Eng., 44, 1-12, https://doi.org/10.1117/1.1887195, 2005.

Bernhard, G., Booth, C. R., Ehramjian, J. C., and Quang., V. V.: NSF Polar Programs UV Spectroradiometer Network 20062007, Operations Report, 16, Biospherical Instruments Inc., San Diego, available at: http://uv.biospherical.com/report_0607/ CHAPTER4.PDF (last access: 30 March 2020), 2008.

Bernhard, G., Fioletov, V., Grooss, J.-U., Ialongo, I., Johnsen, B., Lakkala, K., Manney, G., and Müller, R.: Ozone and UV radiation [in State of the Climate in 2018], B. Am. Meteorol. Soc., 100, S165-S168, https://doi.org/10.1175/2019BAMSStateoftheClimate.1, 2019.

Booth, C. R., Lucas, T. B., Morrow, J. H., Weiler, C. S., and Penhale, P. A.: The United States National Science Foundation's Polar Network for Monitoring Ultraviolet Radiation, American Geophysical Union, Washington, D.C., USA, 1994.

Bromwich, D. H., Nicolas, J. P., Hines, K. M., Kay, J. E., Key, E. L., Lazzara, M. A., Lubin, D., McFarquhar, G. M., Gorodetskaya, I. V., Grosvenor, D. P., Lachlan-Cope, T., and van Lipzig, N. P. M.: Tropospheric clouds in Antarctica, Rev. Geophys., 50, RG1004, https://doi.org/10.1029/2011RG000363, 2012.
Dahlback, A.: Measurements of biologically effective UV doses, total ozone abundances, and cloud effects with multichannel, moderaate bandwidth filter instruments, Appl. Opt., 35, 6514-6521, 1996.

Farman, J. C., Gardiner, B. G., and Shanklin, J. D.: Large losses of total ozone in Antarctica reveal seasonal $\mathrm{ClO}_{x} / \mathrm{NO} x$ interaction, Nature, 315, 207-210, 1985.

Feister, U., Cabrol, N., and Häder, D.: UV Irradiance Enhancements by Scattering of Solar Radiation from Clouds, Atmosphere, 6, 1211-1228, https://doi.org/10.3390/atmos6081211, 2015.

Fioletov, V., Kerr, J., and Fergusson, A.: The UV Index: Definition, Distribution and Factors Affecting It, Can. J. Public Health, 101, 5-9, 2010.

Gorodetskaya, I. V., Van Lipzig, N. P. M., Van den Broeke, M. R., Mangold, A., Boot, W., and Reijmer, C. H.: Meteorological regimes and accumulation patterns at Utsteinen, Dronning Maud Land, East Antarctica: Analysis of two contrasting years, J. Geophys. Res.-Atmos., 118, 1700-1715, https://doi.org/10.1002/jgrd.50177, 2013.

Herenz, P., Wex, H., Mangold, A., Laffineur, Q., Gorodetskaya, I. V., Fleming, Z. L., Panagi, M., and Stratmann, F.: CCN measurements at the Princess Elisabeth Antarctica research station during three austral summers, Atmos. Chem. Phys., 19, 275-294, https://doi.org/10.5194/acp-19-275-2019, 2019.

Høiskar, B. A. K., Haugen, R., Danielsen, T., Kylling, A., Edvardsen, K. are, Dahlback, A., Johnsen, B., Blumthaler, M., and Schreder, J.: Multichannel moderate-bandwidth filter instrument for measurement of the ozone-column amount, cloud transmittance, and ultraviolet dose rates, Appl. Optics, 42, 3472-3479, https://doi.org/10.1364/AO.42.003472, 2003.

Hülsen, G. and Gröbner, J.: Characterization and calibration of ultraviolet broadband radiometers measuring erythemally weighted irradiance, Appl. Optics, 46, 5877-5886, https://doi.org/10.1364/AO.46.005877, 2007.

IPCC: Climate Change 2014: Synthesis Report. Contribution of Working Groups I, II and III to the Fifth Assessment Report of the Intergovernmental Panel on Climate Change, edited by: Core Writing Team, Pachauri, R. K., and Meyer, L. A., IPCC, Geneva, Switzerland, 151 pp., 2014.

Johnsen, B., Mikkelborg, O., Hannevik, M., Nilsen, L. T., Saxeboel, G., and Blaasaas, K. G.: The Norwegian UV-monitoring program Period 1995/96 to 2001, Norway, available at: https:/www.dsa.no/publication/straalevernrapport-2002-4-thenorwegian-uv-monitoring-program-period-1995-96-to-2001.pdf (last access: 19 May 2020), 2002.

Jokela, K., Ylianttila, L., Visuri, R., Leszczynski, K., Kärhä, P., and Ikonen, E.: Intercomparison of lamp and detector-based UV-irradiance scales for solar UV radiometry, J. Geophys. Res.-Atmos., 105, 4821-4827, https://doi.org/10.1029/1999JD900398, 2000.

Kerr, J. B.: Understanding the factors that affect surface ultraviolet radiation, Opt. Eng., 44, 041002, https://doi.org/10.1117/1.1886817, 2005.

Kylling, A., Dahlback, A., and Mayer, B.: The effect of clouds and surface albedo on UV irradiances at a high latitude site, Geophys. Res. Lett., 27, 1411-1414, https://doi.org/10.1029/1999GL011015, 2000. 
Lait, L. R.: An Alternative Form for Potential Vorticity, J. Atmos. Sci., 51, 1754-1759, https://doi.org/10.1175/15200469(1994)051<1754:AAFFPV>2.0.CO;2, 1994.

Lakkala, K., Redondas, A., Meinander, O., Torres, C., Koskela, T., Cuevas, E., Taalas, P., Dahlback, A., Deferrari, G., Edvardsen, K., and Ochoa, H.: Quality assurance of the solar UV network in the Antarctic, J. Geophys. Res.-Atmos., 110, D15101, https://doi.org/10.1029/2004JD005584, 2005.

Lakkala, K., Redondas, A., Meinander, O., Thölix, L., Hamari, B., Almansa, A. F., Carreno, V., García, R. D., Torres, C., Deferrari, G., Ochoa, H., Bernhard, G., Sanchez, R., and de Leeuw, G.: UV measurements at Marambio and Ushuaia during 2000-2010, Atmos. Chem. Phys., 18, 16019-16031, https://doi.org/10.5194/acp-18-16019-2018, 2018.

Lakkala, K., Aun, M., Sanchez, R., Bernhard, G., Asmi, E., Meinander, O., Nollas, F., Hülsen, G., Karppinen, T., Aaltonen, V., Arola, A., and de Leeuw, G.: New continuous total ozone, UV, VIS and PAR measurements at Marambio, $64^{\circ} \mathrm{S}$, Antarctica, Earth Syst. Sci. Data, 12, 947-960, https://doi.org/10.5194/essd12-947-2020, 2020.

Levelt, P. F., Joiner, J., Tamminen, J., Veefkind, J. P., Bhartia, P. K., Stein Zweers, D. C., Duncan, B. N., Streets, D. G., Eskes, H., van $\operatorname{der}$ A, R., McLinden, C., Fioletov, V., Carn, S., de Laat, J., DeLand, M., Marchenko, S., McPeters, R., Ziemke, J., Fu, D., Liu, X., Pickering, K., Apituley, A., González Abad, G., Arola, A., Boersma, F., Chan Miller, C., Chance, K., de Graaf, M., Hakkarainen, J., Hassinen, S., Ialongo, I., Kleipool, Q., Krotkov, N., Li, C., Lamsal, L., Newman, P., Nowlan, C., Suleiman, R., Tilstra, L. G., Torres, O., Wang, H., and Wargan, K.: The Ozone Monitoring Instrument: overview of 14 years in space, Atmos. Chem. Phys., 18, 5699-5745, https://doi.org/10.5194/acp18-5699-2018, 2018.

Levy, R. C., Mattoo, S., Munchak, L. A., Remer, L. A., Sayer, A. M., Patadia, F., and Hsu, N. C.: The Collection 6 MODIS aerosol products over land and ocean, Atmos. Meas. Tech., 6, 29893034, https://doi.org/10.5194/amt-6-2989-2013, 2013.

Levy, R. C., Mattoo, S., Sawyer, V., Shi, Y., Colarco, P. R., Lyapustin, A. I., Wang, Y., and Remer, L. A.: Exploring systematic offsets between aerosol products from the two MODIS sensors, Atmos. Meas. Tech., 11, 4073-4092, https://doi.org/10.5194/amt-11-4073-2018, 2018.

Lopez, M. L., Palancar, G. G., and Toselli, B. M.: Effect of different types of clouds on surface UV-B and total solar irradiance at southern mid-latitudes: CMF determinations at Cordoba, Argentina, Atmos. Environ., 43, 3130-3136, 2009.

Mayer, B. and Kylling, A.: Technical note: The libRadtran software package for radiative transfer calculations - description and examples of use, Atmos. Chem. Phys., 5, 1855-1877, https://doi.org/10.5194/acp-5-1855-2005, 2005.

McKenzie, R. L., Aucamp, P. J., Bais, A. F., Björn, L. O., Ilyas, M., and Madronich, S.: Ozone depletion and climate change: impacts on UV radiation, Photochem. Photobiol. Sci., 10, 182-198, https://doi.org/10.1039/C0PP90034F, 2011.

McKinlay, A. F. and Diffey, B. L.: A Reference Action Spectrum for Ultraviolet Induced Erythema in Human Skin, CIE Journal, 6, 17-22, 1987

McPeters, R. D., Frith, S., and Labow, G. J.: OMI total column ozone: extending the long-term data record, Atmos. Meas. Tech., 8, 4845-4850, https://doi.org/10.5194/amt-8-4845-2015, 2015.
Meinander, O., Kontu, A., Lakkala, K., Heikkilä, A., Ylianttila, L., and Toikka, M.: Diurnal variations in the UV albedo of arctic snow, Atmos. Chem. Phys., 8, 6551-6563, https://doi.org/10.5194/acp-8-6551-2008, 2008.

Montzka, S. A., Dutton, G. S., Yu, P., Ray, E., Portmann, R. W., Daniel, J. S., Kuijpers, L., Hall, B. D., Mondeel, D., Siso, C., Nance, J. D., Rigby, M., Manning, A. J., Hu, L., Moore, F., Miller, B. R., and Elkins, J. W.: An unexpected and persistent increase in global emissions of ozone-depleting CFC-11, Nature, 557, 413-417, https://doi.org/10.1038/s41586-018-0106-2, 2018.

Pattyn, F., Matsuoka, K., and Berte, J.: Glacio-meteorological conditions in the vicinity of the Belgian Princess Elisabeth Station, Antarctica, Antarct. Sci., 22, 79-85, https://doi.org/10.1017/S0954102009990344, 2010.

Sabburg, J. and Calbo, J.: Five years of cloud enhanced surface UV radiation measurements at two sites (in the Northern and Southern Hemispheres), Atmos. Res., 93, 902-912, 2009.

Schoeberl, M. R. and Hartmann, D. L.: The Dynamics of the Stratospheric Polar Vortex and Its Relation to Springtime Ozone Depletions, Science, 251, 46-52, https://doi.org/10.1126/science.251.4989.46, 1991.

Seckmeyer, G., Erb, R., and Albold, A.: Transmittance of a cloud is wavelength-dependent in the UV-range, Geophys. Res. Lett., 23 , 2753-2755, 1996.

Seckmeyer, S., Bais, A., Bernhard, G., Blumthaler, M., Johnsen, B., Lantz, K., and McKenzie, R.: Instruments to Measure Solar Ultraviolet Radiation, Part 3: Multi-channel filter instruments, World Meteorological Organization (WMO), Global Atmosphere Watch Report No. 190, Switzerland, 2010.

Sogacheva, L., Popp, T., Sayer, A. M., Dubovik, O., Garay, M. J., Heckel, A., Hsu, N. C., Jethva, H., Kahn, R. A., Kolmonen, P., Kosmale, M., de Leeuw, G., Levy, R. C., Litvinov, P., Lyapustin, A., North, P., Torres, O., and Arola, A.: Merging regional and global aerosol optical depth records from major available satellite products, Atmos. Chem. Phys., 20, 2031-2056, https://doi.org/10.5194/acp-20-2031-2020, 2020.

Solomon, S., Ivy, D. J., Kinnison, D., Mills, M. J., Neely, R. R., and Schmidt, A.: Emergence of healing in the Antarctic ozone layer, Science, 353, 269-274, https://doi.org/10.1126/science.aae0061, 2016.

Sztipanov, M., Tumeh, L., Li, W., Svendby, T., Kylling, A., Dahlback, A., Stamnes, J. J., Hansen, G., and Stamnes, K.: Ground-based measurements of total ozone column amount with a multichannel moderate-bandwidth filter instrument at the Troll research station, Antarctica, Appl. Optics, 59, 97-106, https://doi.org/10.1364/AO.59.000097, 2020.

UNEP: Environmental Effects of Ozone Depletion: 1998 Assessment, United Nations Environment Programme, Kenya, 205 pp. ISBN 92-807-1724-3, 1998.

Wei, J., Peng, Y., Mahmood, R., Sun, L., and Guo, J.: Intercomparison in spatial distributions and temporal trends derived from multi-source satellite aerosol products, Atmos. Chem. Phys., 19, 7183-7207, https://doi.org/10.5194/acp-19-7183-2019, 2019.

WHO: World Health Organization, World Meteorological Organization, United Nations Environment Programme and International Commission on Non-Ionizing Radiation Protection: Global solar UV index?: a practical guide, World Health Organization, Geneva, Switzerland, 2002. 
WMO: GAW Report, WMO-UMAP Workshop on Broad-Band UV Radiometers, 22-23 April 1996, Garmisch-Partenkirchen, Germany, 1997.

WMO: International Cloud Atlas: Manual on the Observation of Clouds and Other Meteors., available at: https://library.wmo.int/index.php?lvl=notice_display\&id=

5357ICA-New-classifications.html\#.XQj594hKjIU (last access: 20 February 2020), 2017.
WMO: Scientific Assessment of Ozone Depletion: 2018 , Executive Summary, WMO/UNEP, available at: https: //wedocs.unep.org/bitstream/handle/20.500.11822/26858/

SAOD-2018.pdf?sequence $=1 \&$ isAllowed $=y$ (last access: 19 May 2020), 2018. 